九州大学学術情報リポジトリ

Kyushu University Institutional Repository

\title{
Induction of chromosome aberrants in rice (Orgza sativa L.) by using irradiated pollen
}

Wang, Zi-Xuan

Plant Breeding Laboratory, Faculty of Agriculture, Kyushu University

Iwata, Nobuo

Plant Breeding Laboratory, Faculty of Agriculture, Kyushu University

Sukekiyo, Yasunori

Plantech research Institute

Yoshimura, Atsushi

Plant Breeding Laboratory, Faculty of Agriculture, Kyushu University

https://doi.org/10.5109/23974

出版情報 : 九州大学大学院農学研究院紀要. 36 (1/2)，pp. 99-108，1991-10. Kyushu University バージョン：

権利関係 : 


\title{
Induction of chromosome aberrants in rice (Oryza sativa L.) by using irradiated pollen
}

\author{
Zi-Xuan Wang, Nobuo Iwata, Yasunori Sukekiyo* \\ and Atsushi Yoshimura \\ Plant Breeding Laboratory, Faculty of Agriculture, \\ Kyushu University 46-01, Fukuoka 812, Japan \\ (Received July 22, 1991)
}

\begin{abstract}
Rice stocks carrying one or more recessive marker genes were fertilized with pollen of a stock carrying normal alleles at the corresponding loci, that had been preirradiated with gamma rays. Plants derived from such hybridization were investigated for their marker genes, morphological features and seed fertility. Fifty-two pseudo-dominant plants for 9 marker genes were detected from 13,063 plants of 10 cross combinations, and a number of other plants that did not show pseudo-dominant for any marker genes but had variations in morphological features and/or seed fertility, were also obtained. The chromosome number of those plants were counted in the root tip cells, and plants with $2 n=12,2 n=23$, $2 \mathrm{n}=23+1 \mathrm{Fr}$ (fragment chromosome), $2 \mathrm{n}=23+2 \mathrm{Fr}, 2 \mathrm{n}=23+3 \mathrm{Fr}, 2 \mathrm{n}=25$, and chromosome interchange heterozygous, were observed. This study suggests that the use of irradiated pollen is an effective method for inducing chromosome aberration, such as chromosome deficiency, monosomics and chromosome interchange in rice (Oryza sativa L.).
\end{abstract}

\section{INTRODUCTION}

Linkage studies in rice (Oryza sativa L.) have been carried out for decades. Nagao and Takahashi (1963) tentatively proposed twelve linkage maps corresponding to haploid chromosome numbers $(n=12)$, though no cytological evidence was shown. Since then the relationship of the linkage groups to individual chromosomes has been studied by many researchers using reciprocal translocations and trisomics (Iwata and Omura 1971a, b, 1975, 1976 ; Iwata et al. 1984 ; Kinoshita et al. 1975 ; Sato 1976 ; Sato et al. 1973, 1975 ; Yoshimura et al. 1982). Great progress has been made in this field with the achievement of a trisomic series in rice, leading to the establishment of the relationship between the linkage maps and their chromosomes (Iwata and Omura 1984 ; Khush et al. 1984). However, the centromere position and orientation of those maps have yet to be determined.

In order to map centromeres of each chromosomes and to determine the orientation of linkage maps, we conducted an experiment in which a segmental deficiency in specific chromosome regions was obtained by means of the "pseudo-dominant technique", i. e., stocks carrying one or more recessive marker genes were fertilized with irradiated pollen of a stock carrying normal alleles at corresponding loci. This paper reports the results of cytological investigation of plants derived from the cross

*Plantech research Institute, c/o MC-Research center, 1000-Kamoshita-cho, Midori-ku, Yokohama 227, Japan. 
combination between marker gene lines and irradiated pollen.

\section{MATERIALS AND METHODS}

\section{Genotypes and phenotypes of parental cultivars}

Several marker gene lines (FL lines), preserved at the Breeding Laboratory of Kyushu University, were used as female parents. A rice cultivar, Taichung 65, was used as male parent. Each of the marker gene lines used in the experiment had two or more homozygous recessive marker genes, which were located in different chromosomes. In order to detect pseudo-dominant plants early, the marker genes expressing themselves at the seedling stage, such as marker genes for chlorophyll and leaf features, were mainly selected. The male parent, Taichung 65, always has homozygous dominant alleles for each of the marker genes of female parents.

\section{Pollen irradiation and pollination}

Taichung 65 plants at flowering stage were exposed to gamma rays from a ${ }^{60} \mathrm{Co}$ source emitting at rate of $\mathbf{1 3 7 . 7} \mathrm{R} / \mathrm{min}$ in ${ }^{60} \mathrm{Co}$ irradiation Laboratory of Kyushu University. Irradiation doses of $5 \mathrm{kR}$ and $10 \mathrm{kR}$ were used in 1984 and 1986, and one of $5 \mathrm{kR}$ was used in 1987 and 1988. Panicles flowering on the following day were used to pollinate the emasculated florets of marker gene line. $M_{1}$ seeds $(F$, seeds from the crosses between marker gene lines and irradiated Taichung 65) were harvested 30-35 days after pollination for sowing the next year.

\section{Morphological observation}

$\mathrm{M}_{1}$ seeds were first sown on media containing $0.3 \%$ agar for germination in the light-incubator at $25^{\circ} \mathrm{C}$. Germinated seeds were then transferred to nursery in greenhouse. When seedling grew to 5-7 leaves, investigation was done on the marker genes and morphological features. Plants which showed pseudo-dominant for marker genes, very weak nonpseudo-dominant for marker genes, or unique morphological features, were picked up and transferred to nurse-field for special management. Plants showing normal morphological features were transplanted to usual field, and another investigation was made on their morphological features and seed fertility after mature. Plants showed unique features and/or highly and completely sterility in this stage were also picked up. These abnormal plants were vegetatively maintained for cytological and genetical investigations.

\section{Cytology}

For mitotic studies, root tips of abnormal plants were used, and the method of making chromosome preparation followed that of Kurata and Omura (1978). Root tips were pretreated with $1.5 \mathrm{mM}$ 8-hydroxyquinoline for $2.0-3.0$ hours at $20^{\circ} \mathrm{C}$, fixed with ethanol acetic acid $(3: 1 \mathrm{v} / \mathrm{v})$ for $2-24$ hours at $4^{\circ} \mathrm{C}$, and then enzyme-treated with an enzyme mixture of $4 \%$ cellulase RS and $2 \%$ pectolyase $\mathrm{Y}-23$ at $37^{\circ} \mathrm{C}$ for 60 minutes. Chromosome preparations were stained with $1 / 20$ Giemsa's solution at $20^{\circ} \mathrm{C}$ for 1 hour, and then examined with Nikon photomicroscope.

For meiotic studies, pollen mother cells (PMCs) were squashed in $0.1 \%$ acetic carmine and examined with phase contrast microscope. 


\section{RESULTS}

\section{Irradiation effects}

The present study shows that the effectiveness of hybridization with irradiated pollen was as high as that of with nonirradiated pollen, and that most of the $\mathrm{M}_{1}$ seeds produced from such hybridization were apparently normal $F_{1}$ seeds having well-filled endosperm. Shrivelled seeds with collapsed endosperm, which either failed to germinate or germinated but failed to give seedlings, were also observed at a low rate. The germination rate of $\mathrm{M}_{1}$ seeds of above $90 \%$, was as high as that of normal $F_{1}$ seeds. Furthermore, there was no difference between the irradiated doses of $5 \mathrm{kR}$ and $10 \mathrm{kR}$ on seed germination rate, $M_{1}$ plants (plants derived from $M_{1}$ seeds) survival rate and the rate of abnormal plants in the experiment of 1986 (Table 1).

Table 1. Dosage effects on frequencies of $M$, seed germination, $M_{1}$ survival plants and abnormal plants*

\begin{tabular}{ccccc}
\hline $\begin{array}{c}\text { Dosage } \\
(\mathrm{kR})\end{array}$ & $\mathrm{M}_{1}$ seeds & $\begin{array}{c}\text { Germinated } \\
\text { seeds }\end{array}$ & $\begin{array}{c}\text { Survival } \\
\text { plants }\end{array}$ & $\begin{array}{c}\text { Abnormal } \\
\text { plants }\end{array}$ \\
\hline 5 & 835 & $792(95 \%)$ & $788(98 \%)$ & $29(3.68 \%)$ \\
10 & 606 & $576(95 \%)$ & $568(99 \%)$ & $32(5.63 \%)$ \\
\hline
\end{tabular}

: 1986 data.

\section{Pseudo-dominant plants in $M_{1}$ plants}

Two kinds of pseudo-dominant plants were observed in the $\mathrm{M}_{1}$ plants : those which expressed all of the marker genes of the female parents accompanied by normal seed fertility or completely seed sterility, and those which expressed a part of the marker genes of the female parents accompanied by high or complete sterility and/or unique morphological features.

Plants which expressed all of the marker genes and had normal fertility were considered to be self progenies of the female parents and discarded. The other pseudodominant individuals were considered to be breeding true and preserved for further investigations. In four years of experiment, 52 such plants were obtained from 13,063 $\mathrm{M}_{1}$ seeds of 10 cross combinations. The frequency of such pseudo-dominant plants is $0.39 \%$ (Table 2). In the cross combination of FL $26(d l, d-18)$ as female parent, there was one pseudo-dominant plant for marker gene $d l$ (drooping leaf) and 3 plants for $d^{-}$ 18 (dwarf 18) ; in FL 60 ( $\lg , c h-1)$ there were 6 plants for $\lg$ (liguleless), 6 plants for ch-1(chlorina-1) and one plant for $\mathrm{Zg}$ and $c h-1$; in FL $84(\lg , w x)$ there were 3 plants for $w x$ (glutinous endosperm) ; in FL $85(d l, w x)$ there was one plant for $w x$; in FL 99 $(l g, d l, d-18)$ there were 3 plants for $l g$; in FL $126(\mathrm{Zg}, \mathrm{La}$, ws) there were 2 plants for $\lg$ and 4 plants for $l a$ ('lazy' growth habit) ; in FL $175(\lg , v-1)$ there were 4 plants for $l g$, one plant for $v-1$ (virescent-1) and 2 plants for $\lg$ and $v-1$; in FL $242(\lg , f l)$ there were 2 plants for $f l$ (faded green leaves) ; in FL 281 ( $l g$, la, v-4) there were 2 plants for $\lg , 2$ plants for $l a, 5$ plants for $l a$ and v-4 (virescent-4) and 3 plants for $\lg , l a$ and $v$ 4 ; and in FL $297(\lg , v-6)$ there was one plant for $\mathrm{Zg}$. Besides expressing pseudodominant for marker genes, these plants always had a high or complete sterility and/ 
Table 2. Number of pseudo-dominant plants detected in the cross combinations between each marker gene line and irradiated Taichung 65

\begin{tabular}{|c|c|c|c|c|c|}
\hline \multirow{2}{*}{$\begin{array}{l}\text { Female parent } \\
\text { and the } \\
\text { marker genes }\end{array}$} & \multicolumn{4}{|c|}{ Phenotype of $\mathrm{M}_{1}$ plants } & \multirow{2}{*}{$\begin{array}{c}\text { Frequency } \\
(\%)\end{array}$} \\
\hline & Normal & & Pseudo- & ominant & \\
\hline $\begin{array}{c}\text { FL } 26 \\
(d l, d-18)\end{array}$ & $\frac{t+t}{697}$ & $\frac{d l+}{1}$ & $\frac{+d-18}{3}$ & & 0.58 \\
\hline $\begin{array}{c}\text { FL } 60 \\
(\lg , c h-1)\end{array}$ & $3 \frac{t+}{9,947}$ & $\frac{\lg t}{6}$ & $\frac{+c h-1}{6}$ & $\frac{\lg c h-1}{1^{*}}$ & 0.32 \\
\hline $\begin{array}{l}\text { FL } 84 \\
(\lg , w x)\end{array}$ & $\frac{t+}{791}$ & $\frac{+w x}{s}$ & & & 0.38 \\
\hline $\begin{array}{l}\text { FL } 85 \\
(d l, w x)\end{array}$ & $\frac{t+t}{446}$ & $\frac{+w x}{1}$ & & & 0.23 \\
\hline $\begin{array}{c}\text { FL } 99 \\
(\lg , d l, d-18)\end{array}$ & $\frac{t+t}{61}$ & $\frac{\lg +t}{3}$ & & & 1.80 \\
\hline $\begin{array}{l}\text { FL } 126 \\
(\lg , l a, w s)\end{array}$ & $\frac{t+t}{1,104}$ & $\frac{\lg t+}{2}$ & $\frac{t a t}{4}$ & & 0.72 \\
\hline $\begin{array}{l}\text { FL } 175 \\
(\lg , v-1)\end{array}$ & $\frac{t+t}{2,295}$ & $\frac{\lg t}{4}$ & $\frac{+\mathrm{v}-1}{1}$ & $\frac{\lg \mathrm{V}-\mathrm{I}}{2^{*}}$ & 0.30 \\
\hline $\begin{array}{l}\text { FL } 242 \\
(\lg , f l)\end{array}$ & $\frac{t+}{90}$ & $\frac{ \pm f l}{2}$ & & & 0.22 \\
\hline $\begin{array}{c}\text { FL } 281 \\
(l g, l a, v-4)\end{array}$ & $\frac{t+t}{2,756}$ & $\frac{\lg +t}{2}$ & $\frac{+l a+}{2}$ & $\frac{+l a \mathrm{v}-4 \lg \text { la v-4 }}{5}$ & 0.43 \\
\hline \multirow[t]{2}{*}{$\begin{array}{l}\text { FL } 297 \\
(\lg , v-6)\end{array}$} & $\frac{t+}{76}$ & $\frac{\lg t}{1}$ & & & 1.30 \\
\hline & 13,063 & & & 2 & 0.39 \\
\hline
\end{tabular}

* : All of them were haploid plants.

or unique morphological features.

To test if they were breeding true or not, test cross or selfed progenies of some pseudo-dominant plants were investigated. Table 3 shows the mode of segregation for genes $l g$ and $c h-1$ in the test cross progenies of an $l g$ pseudo-dominant plant derived from the cross combination of FL 60 ( $\mathrm{lg}$, ch- 1). When the plant used as female parent was crossed with FL 60 (the origin female parent), all of the progenies were recessive for gene $\lg$, and a segregation rate of 1: 1 was observed for gene $\mathrm{d} / \mathrm{l}$ When the plant used as female parent was crossed with FL 58 (dominant for gene $l g$ and recessive for gene $c h-1$ ), all of the progenies were dominant for gene $l g$, and the gene $c h-1$ showed a segregation rate of $1: 1$, which is to be expected in the test cross. Table 4 shows the mode of segregation for genes $l g, l a$ and ws in the selfed progenies of an la pseudodominant plant derived from the cross combination of FL 126 ( $\mathrm{Zg}$, la, ws). Segregation rate of $3: 1$ was observed for genes $\lg$ and ws (white striped leaf), but the gene la showed a deviated segregation rate (dominant : recessive $=7: 101)$. These results revealed that the pseudo-dominant plants were breeding true.

Chromosomes of those pseudo-dominant plants were counted with their root tips. Three kinds of plants were observed, plants with $2 n=24$, plants with $2 n=23+1 F r$ 
Table 3. The segregation of marker genes $\lg$ and $\mathbf{c h}-\mathbf{1}$ in the progenies from test crosses of $l g$ pseudo-dominant plant $\mathrm{M}_{1} 863-1$ \{FL 60 (lg, ch-I) $\times$ Taichung 65 irradiated $\}$ with marker lines FL $60(\lg , \mathrm{ch}-1)$ and FL $58\left(l^{+}, \mathrm{ch}-1\right)$

\begin{tabular}{cccccc}
\hline \multirow{2}{*}{ Cross combination } & Marker & \multicolumn{3}{c}{ Segregation mode } & \multirow{2}{*}{$\boldsymbol{x}^{2}(1: 1)$} \\
\cline { 3 - 5 } & genes & Dominant & Recessive & Total & \\
\hline M & $\lg$ & 0 & 55 & 55 & \\
& ch-1 & 24 & 31 & 55 & 0.891 \\
\hline \multirow{2}{*}{$M_{1} 863-1$ X FL60 } & $\lg$ & 24 & 0 & 24 & \multirow{2}{*}{0.167} \\
\hline
\end{tabular}

Table 4. The segregation of marker genes $l g$, ws and la in the selfed progenies of la pseudodominant plant $\mathrm{M}_{1} 868-1$ \{FL 126 (Zg, ws, la) X Taichung 65 irradiated)

\begin{tabular}{ccccc}
\hline \multirow{2}{*}{$\begin{array}{c}\text { Marker } \\
\text { genes }\end{array}$} & Dominant & Recessive & Total & $\boldsymbol{x}^{2}(3: 1)$ \\
\cline { 2 - 4 } & 79 & 29 & 108 & 0.198 \\
$\lg$ & 78 & 30 & 108 & 0.444 \\
ws & 7 & 101 & 108 & $270.420^{* * *}$ \\
la & 7 & & \\
\hline
\end{tabular}

*** : Significant at $0.1 \%$ level

(fragment chromosome), and plants with $2 n=23$. Fig. 1 A shows somatic chromosomes of a pseudo-dominant plant for $\mathrm{lg}$ from cross combination of FL 60, in which there were 24 chromosomes without any chromosome aberration ; Fig. 1B shows somatic chromosomes of a pseudo-dominant plant for la from cross combination of FL 126, in which there were 23 chromosomes and one fragment chromosome. Fig. 1C shows somatic chromosomes of a pseudo-dominant plant for la from cross combination of FL 126 , in which there were 23 chromosomes.

The 6 plants that showed pseudo-dominant for all of marker genes of their female parents, one plant for $l g$ and $c h-1$ from cross combination of FL 60, 2 plants for $l g$ and $v-1$ from FL 175, and 3 plants for Zg, la and v-4 from FL 281 (Table 3), were completely sterile and looked like haploid plants. Cytological observation revealed that all of them had 12 chromosomes in their root tips cells.

\section{0 ther chromosome aberrants in $M_{1}$ plants}

In the $\mathrm{M}_{1}$ plants, there were also some plants that did not show pseudo-dominant for any marker gene but had a high or complete seed sterility and/or had unique morphological features. Those plants were also picked up and cytologically observed, and the results shown in Table 5. Twenty-nine plants with $2 \mathrm{n}=23,19$ plants with $2 \mathrm{n}=$ $23+1 \mathrm{Fr}$, one plant with $2 \mathrm{n}=23+2 \mathrm{Fr}$, one plant with $2 n=23+3 \mathrm{Fr}$, and one plant with $2 \mathrm{n}=25$, were obtained.

A lot of other plants that showed so-called semisterility were also observed in the $\mathrm{M}_{1}$ plants. Cytological examination of PMCs of those plants revealed that there were 

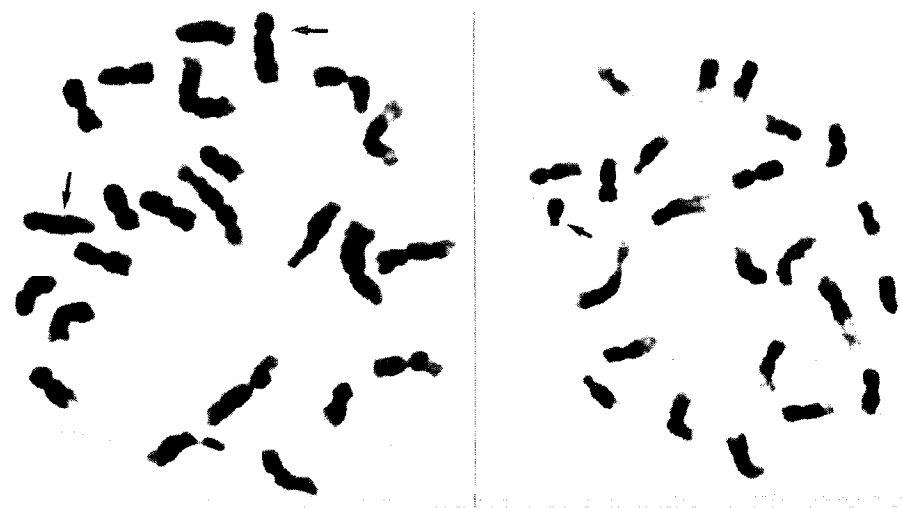

A
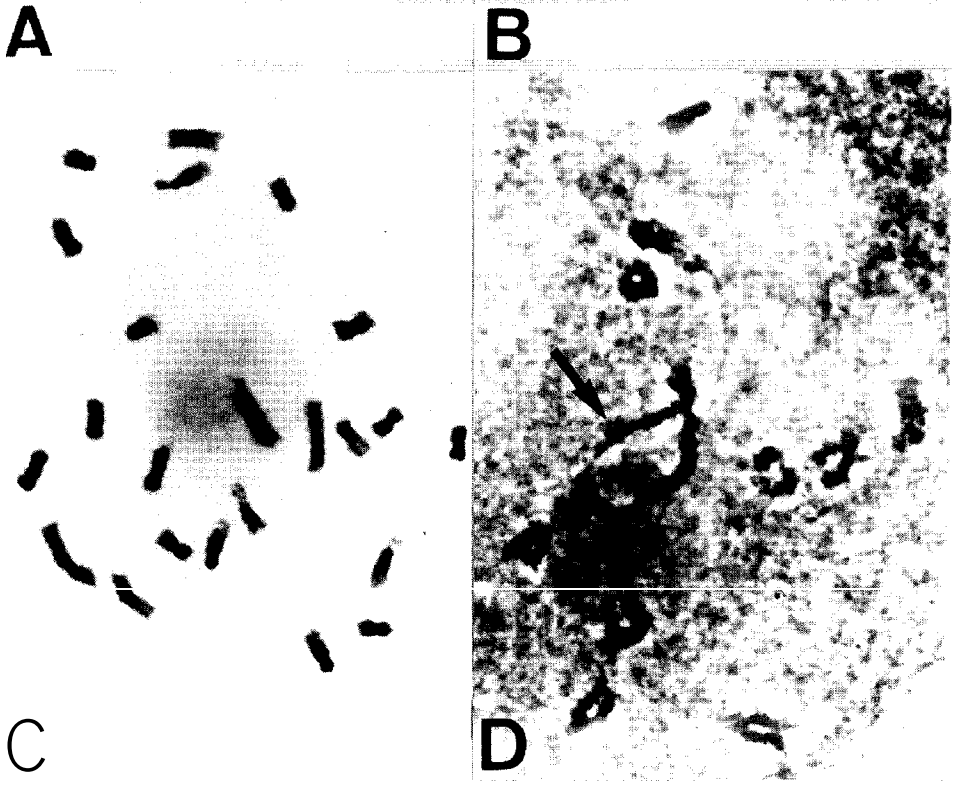

Fig. 1A $\sim$ D. A, Somatic chromosomes of an $\lg$ pseudo-dominant plant derived from the cross combination of FL $60 \times$ Taichung 65 irradiated. There are 24 chromosomes, and no chromosome aberration as far as can be observed under the limitation of photomicroscope. Arrows show chromosome 4, where the gene $\mathrm{lg}$ locates. B, Somatic chromosomes of an la pseudo-dominant plant derived from the cross combination of FL $126 \times$ Taichung 65 irradiated. There are 23 chromosomes and one fragment chromosome. Arrow shows the fragment chromosome. C, Somatic chromosomes of an la pseudo-dominant plant derived from the cross combination of FL $126 \times$ Taichung 65 irradiated. There are 23 chromosomes. D, Chromosome configuration at MI of PMCs of a plant that showed so-called semisterility. There are 10 bivalents and one quadrivalent. Arrow shows the quadrivalent. 
Table 5. Number of plants with chromosomal aberrations detected from $\mathrm{M}_{1}$ plants*

\begin{tabular}{ccccccc}
\hline & \multicolumn{5}{c}{ Number of plants with } \\
\cline { 2 - 6 } & $2 \mathrm{n}=12$ & $2 \mathrm{n}=23$ & $2 \mathrm{n}=23+1 \mathrm{Fr}$ & $2 \mathrm{n}=23+2 \mathrm{Fr}$ & $2 \mathrm{n}=23+3 \mathrm{Fr}$ & $2 \mathrm{n}=25$ \\
1984 & 2 & 3 & 3 & & & \\
1986 & 1 & 4 & 2 & 1 & 1 & 1 \\
1987 & 4 & 16 & 9 & 1 & 1 & 1 \\
1988 & 7 & 29 & 19 & 1 & & \\
Total & & 6 & 9 & & \\
\hline
\end{tabular}

*: Chromosome interchange plants are not included in this list.

10 bivalents and one quadrivalent at metaphase I (Fig. 1D), which is the chromosome configuration expected in meiosis of the translocation heterozygous plant.

\section{Frequency of abnormal plants in $M_{1}$ plants}

In this study, the individuals which were called abnormal plants are those which showed any morphological variation including pseudo-dominant plants, those which showed any seed sterility, and those which showed variation both in morphology and seed fertility. In four years of experiment, a total of 357 such plants were obtained from $21,117 \mathrm{M}_{1}$ seeds. The average frequency of abnormal plants was $1.69 \%$ (Table 6).

Table 6. Numbers of abnormal plants detected from $\mathrm{M}_{1}$ plants

\begin{tabular}{crr} 
Year & M $_{1}$ seeds & Number of abnomal plants \\
\hline 1984 & 7,163 & $35(0.48 \%)$ \\
1986 & 1,441 & $61(5.34 \%)$ \\
1987 & 4,097 & $94(2.29 \%)$ \\
1988 & 8,416 & $167(1.98 \%)$ \\
Total & 21,117 & $357(1.69 \%)$ \\
\hline
\end{tabular}

\section{DISCUSSION}

Among the several cytogenetical technique that can be employed in centromere mapping and determining the orientation of linkage maps, translocation, deficiencies, and trisomics have been used profitably. Extensive use of translocation was made in the study of maize (Anderson and Randolph 1945) and barley (Kasha and Burnham 1965). Telocentrics were used in wheat for locating their respective arms and for determining the orientation of linkage maps (Sears, 1966). Induced deficiencies were utilized for determining the cytological loci of certain marker genes in maize (McClintock, 1931, 1944 ; Singleton, 1939) and tomato (Rick and Khush 1961; Khush and Rick 1968).

In rice, however, there are not enough cytogenetic materials that can be used for centromere mapping studies or for determining the orientation of linkage maps at present. Although reciprocal translocations were used in such studies by Sato et al. 
(1980), since the chromosome of rice is too small to obtain clear cytological evidence by present techniques and since the reciprocal translocation that can be used are few, little progress has been made up to now. Chromosome aberrants are expected to be produced in number in rice.

In this study, we tried to induced chromosome deficiency by using irradiated pollen for the first time in rice. The results reveal that not only chromosome deficiencies, but also monosomics and chromosome interchanges can be obtained by this method.

Of pseudo-dominant plants obtained in the experiment, the plants with $2 \mathrm{n}=24$ should have chromosome deficiencies so small that they can not be detected within the limits of photomicroscope or are merely point mutation induced by irradiation ; the plants with $2 \mathrm{n}=23+1 \mathrm{Fr}$, should have the chromosome deficiencies for the regions of related marker genes; and the plants with $2 n=23$ should be monosomics for the chromosome in which the marker genes locate. Six plants that expressed all marker genes of their female parents and had 12 chromosomes in the root tip cells, should be haploid plants induced by the pollination with irradiated pollen.

Among the pseudo-dominant stated above, those with $2 \mathrm{n}=23+1 \mathrm{Fr}$ could serve as useful materials in the studies of centromere mapping and determining the orientation of linkage maps. By analyzing pachytene chromosomes of those plants, the arm position of the region including given marker genes in their chromosomes and the position of centromeres can be determined.

Plants with $2 \mathrm{n}=23+1 \mathrm{Fr}$ but showed nonpseudo-dominant for any marker genes could also be useful materials in such studies. By the aid of techniques such as RFLP (restriction fragment length polymorphism) analysis and in situ hybridzation, the kind of fragment chromosome can be identified, and information about the related chromosome can be obtained.

The plants having 10 bivalents and one quadrivalent at metaphase I of PMCs in meiosis should be translocation heterozygous plants. This kind of plant appeared frequently in $\mathrm{M}_{1}$ plants, which suggests that the use of irradiated pollen is an effective method for production of chromosome interchange in rice.

Since the marker gene lines used in the experiment were diploid plants, most of the chromosome aberrants obtained in this study were weak or had poor seed fertility. This makes preservation and further studies difficult. However, trisomics should be less sensitive to the irradiation because of their extra chromosomes. If the trisomics having homozygous recessive marker genes in the related chromosome can be used in such studies, monotelotrisomics showing pseudo-dominant for marker genes can be expected, which should have better seed fertility and more useful for research. It is recommended that trisomics having homozygous recessive marker genes in their related chromosome be used as female parents instead of diploid marker gene lines in such studies.

In conclusion, this study suggests that the use of irradiated pollen is an effective method for inducing chromosome aberrants, such as chromosome deficiencies, monosomics and chromosome interchange in rice.

Irradiated pollen have also been used to transfer limited genetic fragment from one variety to another, as originally proposed by Pandey (1975). The possibility of such an approach in rice was tried by Chin and Gordon (1989a, b), who suggested that the method of pollination with irradiation was not promising for rice breeding. They also 
observed no haploid plants or chromosome aberration in $\mathrm{M}_{1}$ plants. However, contrary to their findings, the results of the present study reveal that not only haploid plants $(6 / 21,117)$ but also a number of chromosome aberrations were produced as a result of this process.

\section{REFERENCES}

Anderson, E. G. and L. F. Randolph 1945 Location of the centromeres on the linkage maps of maize. Genetics, $30: 518-526$

Chin, S. F. and G. H. Gordon 1989a Pollination with irradiated pollen in rice -Oryza sativa L. I. First $\left(\mathrm{M}_{1}\right)$ generation. Heredity, $63: 163-170$

Chin, S. F. and G. H. Gordon $1989 \mathrm{~b}$ Pollination with irradiated pollen in rice -Oryza sativa L. II. The second (M,) generation. Heredity, $63: 171-179$

Iwata, N. and T. Omura 1971a Linkage analysis by reciprocal translocation method in rice plants (Oryza sativa L.). I Linkage groups corresponding to the chromosome 1, 2, 3 and 4. Japan, J. Breed., 21: 19-28 (in Japanese with English summary)

Iwata, N. and T. Omura 1971b Linkage analysis by reciprocal translocation method in rice plants (Oryza sativa L.). II. Linkage groups corresponding to chromosome 5, 6, 8, 9, 10 and 11. Sci. Bull. Fac. Agr., Kyushu Univ., 25: 137-153 (in Japanese with English summary)

Iwata, N. and T. Omura 1975 Studies on the trisomics in rice plants (Oryza sativa L.). III. Relation between trisomics and genetic linkage groups. Japan J. Breed., $25: 363-368$

Iwata, N. and T. Omura 1976 Studies on the trisomics in rice plants (Oryza sativa L.). V. On the possibility of association of three linkage groups with one chromosome. Jpn. J. Genet., 51: 135137

Iwata, N. and T. Omura 1984 Studies on the trisomics in rice plants (Oryza sativa L.). vI. An accomplishment of a trisomic series in japonica rice plants. Jpn. J. Genet., 59 : 199-204

Iwata, N., H. Satoh and T. Omura 1984 Relationship between the twelve chromosomes and the linkage groups. (Studies on the trisomics in rice plants (Oryza sativa L.) V .) Japan. J. Breed., 34 : 314-321

Kasha, K. J. and C. R. Burnham 1965 The location of interchange breakpoints in barley. 1. Linkage studies and map orientation. Canad. J. Genet. Cytol., 7: 62-77

Khush, G. S. and C. M. Rick 1968 Cytogenetic analysis of the tomato genome by means of induced deficiencies. Chromosoma, $23: 452-484$

Khush, G. S., R. J. Singh, S. C. Sur and A. L. Librojo 1984 Primary trisomics of rice: Origin, morphology, cytology, and use in linkage mapping. Genetics, $107: 141-163$

Kinoshita, T., M. Takahashi and S. Sato 1975 Linkage analysis by reciprocal translocation method, with special reference to the first linkage group. -Genetical studies on rice plant, LXIV. -Memo. Fac.Agr., Hokkaido Univ., 9: 259-263 (in Japanese with English summary)

Kurata, N. and T. Omura 1978 Karyotype analysis in rice. I A new method for identifying all chromosome pairs. Jpn. J. Genet., 53: 251-255

McClintock, B. 1931 Cytological observations of deficiencies involving known genes, translocations and an inversion in Zea mays. Missouri. Agr. Expt. Sta. Res. Bull., 163: 1-30

McClintock, B. 1944 The relation of homozygous deficiencies to mutations and allelic series in maize. Genetics, $29: 478-502$

Nagao, S. and M. Takahashi 1963 Trial construction of twelve linkage groups in Japanese rice (Genetical studies on rice plant, XXVII). J.Fac.Agr., Hokkaido Univ., $53: 72-130$

Pandey, K. K. 1975 Sexual transfer of specific genes without gametic fusion. Nature, $256: 310-313$

Rick, C. M. and G. S. Khush 1961 X-ray induced deficiencies of chromosome 11 in the tomato. Genetics, 46: 1389-1393

Sato, S., T. Kinoshita and M. Takahashi 1973 Linkage analysis of rice plant, by the use of Nishimura's 
reciprocalltranslocation lines. -Genetical studies on rice plant, LIX.- Memo. Fac. Agr., Hokkaido Univ., $8: 367-376$ (in Japanese with English summary)

Sato, S., T. Kinoshita and M. Takahashi 1975 Linkage analysis of rice plant by the use of reciprocal translocation lines induced from linkage testers. -Genetical studies on rice plant, LXII.Memo. Fac. Agr., Hokkaido Univ., 9: 193-199 (in Japanese with English summary)

Sato, S. 1976 Linkage analysis of rice plant, by the use of reciprocal translocation lines. Bull. Coll. Agr., Univ. Ryukyus, 23: 73-104 (in Japanese with English summary)

Sato, S., T. Kinoshita and M. Takahashi 1980 Location of centromere and interchange breakpoints in the pachytene chromosome of rice. Genetical studies on rice plant, LXX I. Japan. J. Breed., 30 : 387-398

Sears, E. R. 1966 Chromosome mapping with the aid of telocentrics. Proc. 2nd Intern. Wheat Genetics Symp. Hereditas (Lund.) Suppl., $2: 370-381$

Singleton, W. R. 1939 Cytological observations on deficiencies produced by treating maize pollen with ultraviolet light. Genetics, $24: 109$

Yoshimura, A., Iwata N. and T. Omura 1982 Linkage analysis by reciprocal translocation method in rice plants (Oryza sativa L.). III. Marker genes located on chromosome 2, 3, 4, and 7. Japan. J. Breed., 32: 323-332 